\title{
Efficient Discrimination of Some Moss Species by Fourier Transform Infrared Spectroscopy and Chemometrics
}

\author{
Zhen Cao, ${ }^{1,2}$ Yongying Liu, ${ }^{3}$ and Jiancheng Zhao ${ }^{1}$ \\ ${ }^{1}$ College of Life Science, Hebei Normal University, Shijiazhuang 050024, China \\ ${ }^{2}$ Hebei Women's Vocational College, Shijiazhuang 050091, China \\ ${ }^{3}$ Department of Biology, Jiaozuo Teachers College, Jiaozuo 454001, China
}

Correspondence should be addressed to Jiancheng Zhao; zhaojiancheng@hebtu.edu.cn

Received 21 March 2014; Revised 26 June 2014; Accepted 29 June 2014; Published 14 July 2014

Academic Editor: Feride Severcan

Copyright (C) 2014 Zhen Cao et al. This is an open access article distributed under the Creative Commons Attribution License, which permits unrestricted use, distribution, and reproduction in any medium, provided the original work is properly cited.

\begin{abstract}
Fourier transform infrared spectroscopy (FTIR) technique was used to classify 16 species from three moss families (Mielichhoferiaceae, Bryaceae, and Mniaceae). The FTIR spectra ranging from $4000 \mathrm{~cm}^{-1}$ to $400 \mathrm{~cm}^{-1}$ of the 16 species were obtained. To group the spectra according to their spectral similarity in a dendrogram, cluster analysis and principal component analysis (PCA) were performed. Cluster analysis combined with PCA was used to give a rough result of classification among the moss samples. However, some species belonging to the same genus exhibited very similar chemical components and similar FTIR spectra. Fourier selfdeconvolution (FSD) was used to enhance the differences of the spectra. Discrete wavelet transform (DWT) was used to decompose the FTIR spectra of Mnium laevinerve and M. spinosum. Three scales were selected as the feature extracting space in the DWT domain. Results showed that FTIR spectroscopy combined with DWT was suitable for distinguishing different species of the same genus.
\end{abstract}

\section{Introduction}

Mosses are perennial plants, typically $1 \mathrm{~cm}$ to $10 \mathrm{~cm}$ tall, usually occur in large tufts, and concentrate in groups. They possess a gametophyte-dominated life cycle. Spores are released from a sporophyte capsule at certain times. Mosses leaves commonly exhibit a spiral phyllotaxy. Rhizoids are often branched. Given that they do not have any root system and barely no cuticle, mosses obtain most of their nutrients from the atmosphere (wet and dry deposition) [1]. Because of their limited living forms, bryophytes usually grow in harsh habitats, where no vascular plants can live. With over 12,000 species recognized worldwide, mosses are one of the most speciose among plants [2]. They are distributed from the Arctic to the Antarctic and occupy a broad range of habitats. They show extensive morphological and anatomical diversification in both gametophyte and sporophyte organization [3].

The taxonomic concepts and phylogenetic relations among genera of the families Mielichhoferiaceae, Bryaceae, and Mniaceae have given rise to much controversy in recent years [4]. Studies using nuclear, plastid, and mitochondrial sequences showed that many genera of the Mielichhoferioideae and Bryaceae families are polyphyletic [5-8]. Some species of Mielichhoferiaceae, Bryaceae, and Mniaceae are difficult to distinguish by traditional phytotaxonomic methods. For instance, the species of genus Pohlia was originally placed in family Bryaceae according to the characteristics of the leaf cells [9]. A phylogenetic analysis of random amplified polymorphic DNA (RAPD) markers showed that Pohlia was more closely related to the genera of Mniaceae than Bryaceae [4]. However, Wang et al. declared that Pohlia should not be classified in the Mniaceae and was indicated to be a closer relative of genera Mielichhofera (Mielichhoferioideae) $[8,10]$. Fourier transform infrared (FTIR) spectroscopy is an alternative method for species discrimination, which has already been demonstrated for medicinal plants, bacteria, fungi, and microorganisms [11-14]. Although FTIR spectroscopy has made a significant contribution to the plant classification, 
reports on mosses taxonomy by this analytical approach are still rare [15].

FTIR is an original spectroscopic technique used in investigating the functional groups of chemical components $[16$, 17]. It presents good sensitivity and a remarkable simplicity in sample preparation. Each FTIR spectrum of a compound can express a unique "fingerprint." This feature enables FTIR spectroscopy to be used in classification of different samples or identification of unknown samples [18]. However, if differences in the chemical compositions are small, the FTIR spectra will be very similar. Then the analysis of using only FTIR spectra is insufficient to group a set of samples [19]. Chemometric methods combined with FTIR spectroscopy can compensate the defects in single FTIR spectral analysis [20]. The way of using chemometrics to make determination and classification of the confused species becomes an effective research object in the instrument analysis [14, 21]. In our study, the FTIR spectra of some species in families Mielichhoferiaceae, Bryaceae, and Mniaceae were similar. So we chose chemometric methods to further discriminate different species in the three families.

Wavelet transform (WT) is a useful tool for a variety of signal processing applications. For example, WT is useful for the compression of digital image files, noise reduction, and pattern recognition. It provides a time-frequency representation of the signal. It was also developed to overcome the discrimination of nonstationary signals with different frequency features [22]. The signal to be analyzed is multiplied with a wavelet function; the analyzing ability for the same signal of wavelet coefficients is different at different scales. Therefore, the WT coefficients can be considered as the characteristics of the signal. A few features can reflect the major spectral information after a wavelet function; WT can be considered one of the most efficient chemometric methods [23].

Cluster analysis and principal component analysis (PCA) are two other multivariate analyses that can be used to identify natural clustering pattern and group objects on the basis of similarities among the samples [24]. Cluster analysis and PCA are widely recognized as very powerful tools in obtaining information about relations within a dataset [25, 26].

The present study aimed to evaluate the potential use of FTIR spectroscopy combined with cluster analysis and PCA technique for the discrimination of 16 moss species. Fourier self-deconvolution (FSD) and discrete WT (DWT) were used to investigate the variability of the chemical fingerprint among the species.

\section{DWT}

DWT is used to decompose a signal by using filters to extract interesting frequency resolution components within the signal. DWT possesses compact support in both time and frequency domains [27]. It is a signal-processing tool that is used in many engineering, scientific, and mathematical applications. DWT is used to analyze the signal at different frequency bands with different resolutions by decomposing the signal into a coarse approximation and detailed information [28]. DWT originated from the discretization of continuous WT (CWT), and the common discretization is dyadic. CWT is provided by

$$
X_{\mathrm{wt}}(\tau, s)=\frac{1}{\sqrt{|s|}} \int_{-\infty}^{\infty} x(t) \Psi^{*}\left(\frac{t-\tau}{s}\right) d t,
$$

where $x(t)$ is the signal to be analyzed and $\Psi^{*}(t)$ is the mother wavelet or the basis function. All of the wavelet functions used in the transformation are derived from the mother wavelet through translation and scaling.

In CWT, the signals are analyzed using a set of basic functions, which are related to each other by simple scaling and translation. In the case of DWT, a time-scale representation of the digital signal is obtained using digital filtering techniques. The DWT is derived from the discretization of CWT $(\tau, s)$ and the most common discretization is dyadic. DWT is provided by

$$
X_{\mathrm{dwt}}(j, k)=\frac{1}{\sqrt{2^{j}}} \int_{-\infty}^{\infty} x(t) \Psi^{*}\left(\frac{t-2^{j} k}{2^{j}}\right) d t,
$$

where $\tau$ and $s$ are replaced by $2^{j}$ and $2^{j} k$. The DWT is computed by successive low-pass and high-pass filtering of the discrete time-domain signal. This computation is called the Mallat algorithm or Mallat-tree decomposition. Its significance is in the manner it connects the continuous-time multiresolution to discrete-time filters. With this approach, the time resolution becomes arbitrarily good at high frequencies, whereas the frequency resolution becomes arbitrarily good at low frequencies [29].

\section{Materials and Methods}

3.1. Sample Preparation. The 16 species of mosses were collected from Hebei, China, in August 2011. The environmental conditions and population sizes of the sample plants were similar. The geographic coordinates and altitudes are shown in Table 1. The voucher specimens are deposited in the Herbarium of Hebei Normal University.

To avoid problems caused by the influence of water on FTIR spectra, all of the samples were dried at $35^{\circ} \mathrm{C}$ in a drying oven for one week until a constant weight was achieved. The samples were ground into fine powder in an agate mortar and then sieved through 200 meshes $(75 \mu \mathrm{m})$.

3.2. Spectral Measurements. The FTIR spectra (range $4000 \mathrm{~cm}^{-1}$ to $400 \mathrm{~cm}^{-1}, 4 \mathrm{~cm}^{-1}$ resolution, 32 scans) were obtained using a Bruker Optics (Ettlingen, Germany) Vertex70 FTIR spectrometer equipped with a DigiTect detector, which could prevent external signal disturbance and guarantee the highest signal-to-noise ratio. Conventional $\mathrm{KBr}$ pellet spectra were recorded from the sample. After grinding, $2 \mathrm{mg}$ dried sample powder was mixed with $50 \mathrm{mg}$ dried $\mathrm{KBr}$ power and then compressed with the use of an evacuable pellet die to produce a $13 \mathrm{~mm}$ diameter pellet. 
TABLE 1: Description of the geographic coordinates and altitudes of the sample sources.

\begin{tabular}{|c|c|c|c|c|c|c|c|}
\hline $\begin{array}{l}\text { Species } \\
\text { label } \\
\text { number }\end{array}$ & Species & Genera & Family & Site & Altitude ( $\mathrm{m}$ asl) & $\begin{array}{l}\text { Geographic } \\
\text { coordinates }\end{array}$ & $\begin{array}{c}\text { Voucher } \\
\text { specimen } \\
\text { number }\end{array}$ \\
\hline 1 & Pohlia cruda & Pohlia & Mielichhoferiaceae & $\mathrm{HY}$ & 1414 & $39^{\circ} 56^{\prime} \mathrm{N} 114^{\circ} 57^{\prime} \mathrm{E}$ & $2011253 \mathrm{~L}$ \\
\hline 2 & Pohlia longicollis & & & HY & 1294 & $39^{\circ} 56^{\prime} \mathrm{N} 114^{\circ} 56^{\prime} \mathrm{E}$ & $2011103 \mathrm{~L}$ \\
\hline 3 & Pohlia minor & & & $\mathrm{HY}$ & 1342 & $39^{\circ} 56^{\prime} \mathrm{N} 114^{\circ} 57^{\prime} \mathrm{E}$ & $2011305 \mathrm{~L}$ \\
\hline 4 & Pohlia elongata & & & HY & 1460 & $39^{\circ} 56^{\prime} \mathrm{N} 114^{\circ} 58^{\prime} \mathrm{E}$ & $2011016 \mathrm{~L}$ \\
\hline 5 & Bryum argenteum & Bryum & Bryaceae & HY & 1709 & $39^{\circ} 55^{\prime} \mathrm{N} 114^{\circ} 57^{\prime} \mathrm{E}$ & $2011154 \mathrm{~L}$ \\
\hline 6 & Bryum uliginosum & & & HY & 1713 & $39^{\circ} 55^{\prime} \mathrm{N} 114^{\circ} 57^{\prime} \mathrm{E}$ & $2011024 \mathrm{~L}$ \\
\hline 7 & Bryum capillare & & & $\mathrm{HY}$ & 1540 & $39^{\circ} 56^{\prime} \mathrm{N} 114^{\circ} 58^{\prime} \mathrm{E}$ & $20110620 X$ \\
\hline 8 & Mnium spinosum & Mnium & Mniaceae & $\mathrm{HY}$ & 1468 & $39^{\circ} 56^{\prime} \mathrm{N} 114^{\circ} 59^{\prime} \mathrm{E}$ & $20110151 X$ \\
\hline 9 & Mnium laevinerve & & & HY & 1507 & $39^{\circ} 56^{\prime} \mathrm{N} 114^{\circ} 59^{\prime} \mathrm{E}$ & $20110324 X$ \\
\hline 10 & Mnium marginatum & & & HY & 2625 & $39^{\circ} 54^{\prime} \mathrm{N} 114^{\circ} 58^{\prime} \mathrm{E}$ & 20110493X \\
\hline 11 & Plagiomnium acutum & Plagiomnium & & HY & 2483 & $39^{\circ} 54^{\prime} \mathrm{N} 114^{\circ} 58^{\prime} \mathrm{E}$ & 20110648X \\
\hline 12 & Plagiomnium succulentum & & & HY & 1473 & $39^{\circ} 56^{\prime} \mathrm{N} 114^{\circ} 58^{\prime} \mathrm{E}$ & 20110480X \\
\hline 13 & Plagiomnium maximoviczii & & & HY & 1469 & $39^{\circ} 55^{\prime} \mathrm{N} 114^{\circ} 58^{\prime} \mathrm{E}$ & 20110429X \\
\hline 14 & Plagiomnium arbusculum & & & HY & 1517 & $39^{\circ} 55^{\prime} \mathrm{N} 114^{\circ} 59^{\prime} \mathrm{E}$ & 20110457X \\
\hline 15 & Trachycystis flagellaris & Trachycystis & & HY & 1583 & $39^{\circ} 56^{\prime} \mathrm{N} 114^{\circ} 58^{\prime} \mathrm{E}$ & $20110206 \mathrm{X}$ \\
\hline 16 & Trachycystis ussuriensis & & & HY & 1585 & $39^{\circ} 56^{\prime} \mathrm{N} 114^{\circ} 58^{\prime} \mathrm{E}$ & $20110212 X$ \\
\hline
\end{tabular}

HY: Yuxian county, Hebei province, China.

TABLE 2: Moss plant samples (Plagiomnium acutum) collected from different places.

\begin{tabular}{lcccc}
\hline Sample number & Region & Altitude $(\mathrm{m}$ asl $)$ & Time of collection & Voucher specimen number \\
\hline P1 & Pingshan, Hebei & 1516 & 2011.05 & C0215 \\
P2 & Pingshan, Hebei & 1064 & 2011.05 & C0287 \\
P3 & Yuxian, Hebei & 981 & 2011.07 & X0059 \\
P4 & Yuxian, Hebei & 1821 & 2011.07 & X0087 \\
P5 & Zhuolu, Hebei & 1076 & 2011.08 & X0125 \\
\hline
\end{tabular}

The pellets were compressed under the same mechanical pressure, and their FTIR spectra were obtained. The FTIR spectra of the 16 mosses samples were automatically baseline corrected. Background was recorded each time before the measurement and subtracted automatically by the software [30]. Each of the samples was measured three times and the averaged spectrum was obtained for further analysis.

3.3. Precision and Repeatability Test. To validate the method, the FTIR spectra of sample no. 11 (Plagiomnium acutum (Lindb.) T. Kop) were recorded. The precision test was determined by replicate records $(5 x)$ of the same sample. The repeatability test was analyzed by recording the same species from five different areas independently (Table 2). In statistics, the relative standard deviation (RSD or \%RSD) is the absolute value of the coefficient of variation. It is often expressed as a percentage. The RSD is widely used in analytical chemistry to express the precision and repeatability of an assay. In this study, the mean value RSD of transmittances of the communal peaks was calculated.
3.4. Data Analysis. Spectral data were calculated with the use of OMINIC version 8 software (Thermo Fisher, Waltham, USA). Cluster analysis and PCA were conducted with the use of IBM SPSS 19.0 software. Cluster analysis is an undirected, unbiased statistical method used to analyze spectroscopic information and it has been used to sort the FTIR spectra into similar sets or groups [31]. Satisfactory results on FTIR spectra of complex biological molecules have been obtained with Ward's algorithm, Euclidean distances, or correlation coefficient calculation as distance metrics [32, 33]. In the present study, 16 samples of mosses were selected for clustering. The 20 transmittance peaks in the range of $4000 \mathrm{~cm}^{-1}$ to $400 \mathrm{~cm}^{-1}$ were then used for PCA analysis [15]. In order to make the cluster analysis and PCA analysis more accurate, we chose 20 transmittance peaks in the range of $4000 \mathrm{~cm}^{-1}$ to $400 \mathrm{~cm}^{-1}$ for cluster analysis. The nearest neighbor and Pearson correlation were used to construct dendrograms. PCA is a multivariate statistical data reduction method. It transforms the original set of variables to a new set of uncorrelated variables called principal components (PCs) 
[34]. It also provides information on the major spectral components, in which dominant factors determine differences among samples [35-37]. PCA is used to extract the important features of the correlation matrix in terms of PCs. Only a few PCs are usually required to explain the majority of observed variance. PCA can be used as a chemometric method for FTIR analysis. The analysis can be presented as either twodimensional (2D, two PCs) or three-dimensional (3D, three PCs) scatter plots [38]. The 20 selected transmittance peaks were used for PCA and the factor loading was plotted.

FSD was performed using OMINIC version 8 software. DWT was performed using MATLAB 7.1 software. Daubechies wavelet possesses better exploration ability for signal singularity, which has functioned as analysis wavelet. One-dimensional stationary DWT can be performed to different samples [39].

\section{Results and Discussion}

\subsection{Validation of the Method}

4.1.1. Precision Test. The precision test was conducted by replicate measurements of the same sample (Plagiomnium acutum) for five times in a day. The results are shown in Table 3. The RSD of the FTIR transmittances of the communal peaks is $\leq 0.51 \%$.

4.1.2. Repeatability Test. The repeatability of the method was assessed by analyzing five independently prepared samples of Plagiomnium acutum from five different places using the same method (Table 2). The results are shown in Table 3 . The RSD of the FTIR transmittances of the communal peaks is $\leq 2.17 \%$.

The running results show that the FTIR transmittances of the characteristic common peaks of the same species are stable. The method is reliable and exhibits good repeatability; thus, it can be applied in the analysis of other moss samples.

4.2. FTIR Analysis. The FTIR spectra of the 16 samples of mosses were recorded in three sets: four Mielichhoferiaceae samples (Figure 1(a)), three Bryaceae samples (Figure 1(b)), and nine Mniaceae samples (Figures 1(c), 1(d), and 1(e)). The characteristic peaks of the FTIR spectra obtained from the samples are shown at the bottom. Most of these peaks represent major functional groups, which show the comprehensive information of protein, carbohydrate, fibrin, lipid, and so forth. The FTIR spectra comparison can provide information on the different samples. Hence, the region between $4000 \mathrm{~cm}^{-1}$ and $3000 \mathrm{~cm}^{-1}$ presents a broad band centered at approximately $3380 \mathrm{~cm}^{-1}$ corresponding to the transmittance due to the stretching of $\mathrm{O}-\mathrm{H}$ bands (Figure 1) [14]. A sharp peak at $2920 \mathrm{~cm}^{-1}$ is due to the presence of polysaccharide, lipid, and carbohydrates ( $\mathrm{C}-\mathrm{H}$ stretch) [15]. The peak at $1640 \mathrm{~cm}^{-1}$ is attributed to the transmittance of amide (N$\mathrm{H}$ bend). A second amide vibration is shown at $1380 \mathrm{~cm}^{-1}$ (C-N stretch), followed by amide peak at $1250 \mathrm{~cm}^{-1}$ (C$\mathrm{N}$ stretch). The peak at $1040 \mathrm{~cm}^{-1}$ can be attributed to oligosaccharides, glycoprotein, and cellulose (C-O stretch)
TABLE 3: FTIR transmittances of the characteristic common peaks of precision and repeatability tests on Plagiomnium acutum.

\begin{tabular}{lcc}
\hline \multirow{2}{*}{ Peak number } & \multicolumn{2}{c}{ Transmittance \% mean (RSD \%) } \\
& PT & RT \\
\hline 1 & $13.386(0.51)$ & $13.635(0.81)$ \\
2 & $28.041(0.14)$ & $29.163(0.18)$ \\
3 & $52.856(0.12)$ & $53.932(2.17)$ \\
4 & $13.969(0.23)$ & $14.306(0.76)$ \\
5 & $22.608(0.16)$ & $21.652(0.84)$ \\
6 & $10.738(0.33)$ & $10.560(1.42)$ \\
7 & $29.045(0.13)$ & $30.145(0.73)$ \\
8 & $27.033(0.12)$ & $27.145(0.95)$ \\
9 & $25.063(0.15)$ & $25.852(1.07)$ \\
10 & $23.617(0.09)$ & $24.444(1.17)$ \\
\hline Precision test $(\mathrm{PT}, n=5)$, repeatability test $(\mathrm{RT}, n=5)$. &
\end{tabular}

[17]. The peaks from $1200 \mathrm{~cm}^{-1}$ to $400 \mathrm{~cm}^{-1}$ can be attributed to the transmittance of low-molecular weight carbohydrates, polyols, and monosaccharides; this region is characterized as the fingerprint region [15].

4.3. Cluster Analysis. The FTIR spectra from the different species of mosses exhibited similar transmittance. Specific differences were difficult to distinguish by experience. Therefore, we chose multivariate statistical methods to analyze the transmittance bands. Cluster analysis was conducted to investigate the relationships between these taxa. The spectra were classified with the use of the nearest neighbor and Pearson correlation according to the transmittance peaks from $4000 \mathrm{~cm}^{-1}$ to $400 \mathrm{~cm}^{-1}$.

The dendrogram divides the 16 samples into two separated clusters (Figure 2): cluster 1 (C1) comprises the Mielichhoferiaceae and Bryaceae species and cluster 2 (C2) comprises the Minaceae species. C1 is split into two second subclusters. Subcluster 1 (SC1) comprises Bryum argenteum, B. capillare, and B. uliginosum. Subcluster 2 (SC2) contains the three species of genus Pohlia in Mielichhoferiaceae. SC1 and SC2 are close to each other. C2 comprises two subclusters. Scl comprises the three Mnium species and four Plagiomnium species; Sc2 contains the two Trachycystis species (Figure 2). In SC2, Pohlia cruda is clustered with P. longicollis. The result is inconsistent with the molecular result that $P$. cruda is distantly related to the other species of genus Pohlia.

The result basically reflects the relative relationships of the 16 samples; further study is needed for the internal relationships of the genera. Thus, PCA, FSD, and onedimensional DWT were adopted in our study.

4.4. PCA. We used PCA as the second multivariate analysis. The data of the transmittance peaks in the range of $4000 \mathrm{~cm}^{-1}$ to $400 \mathrm{~cm}^{-1}$ in FTIR spectra were analyzed by PCA. Table 4 shows the variance accounted by the first four PCs computed from the transmittance value of characteristic peaks used in cluster analysis. The first three PCs summarize more variation in the data than any other PCs, accounting for more than 


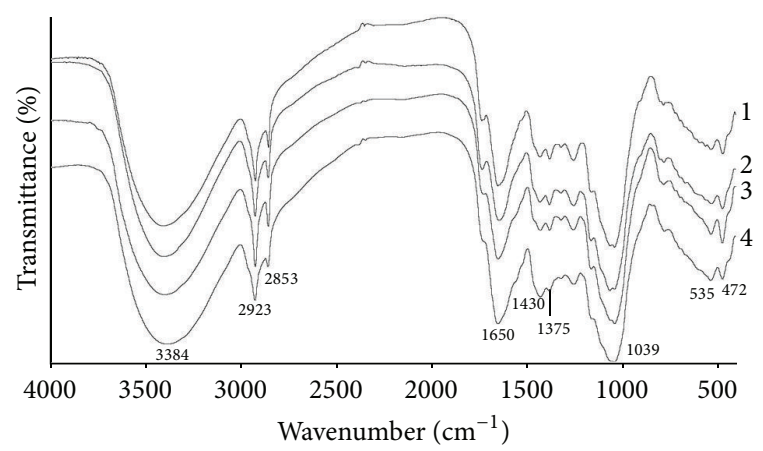

(a)

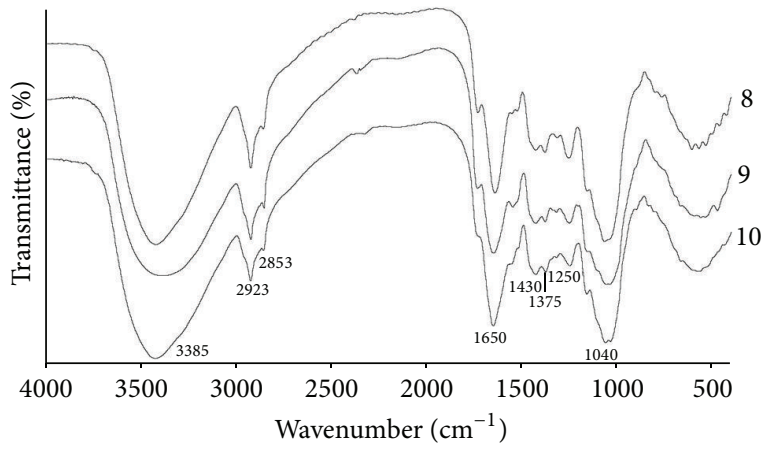

(c)

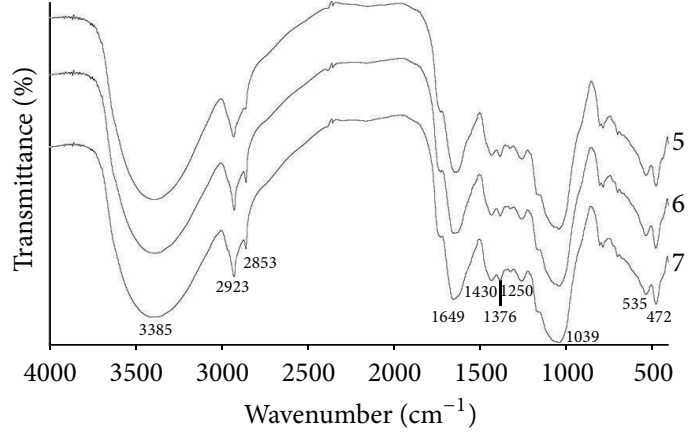

(b)

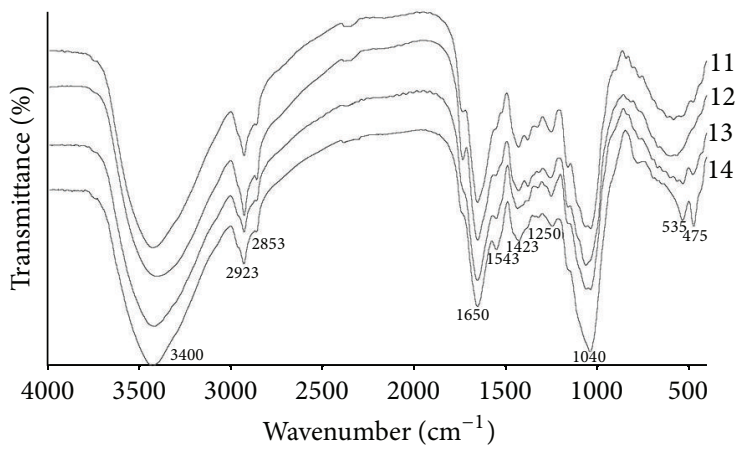

(d)

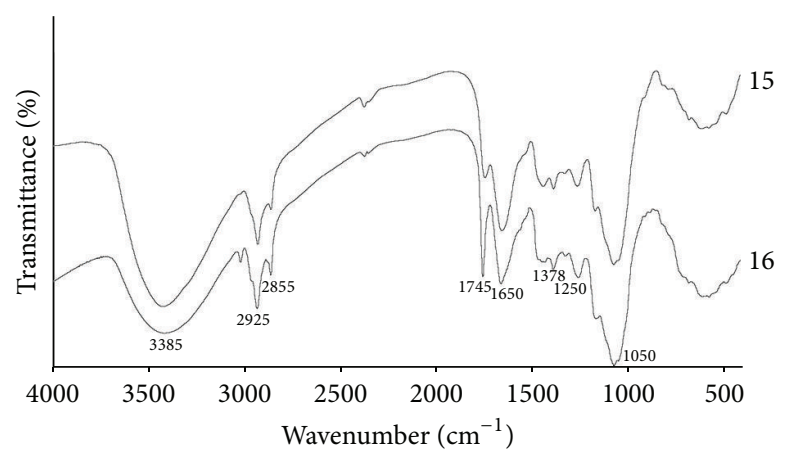

(e)

FIGURE 1: FTIR spectra obtained in the range of $4000 \mathrm{~cm}^{-1}$ to $400 \mathrm{~cm}^{-1}$ for the four species of family Mielichhoferiaceae (a), three species of family Bryaceae (b), and nine species of family Mniaceae (c), (d), (e); the characteristic peaks are indicated at the bottom.

Bryum argenteum Bryum uliginosum Bryum capillare Pohlia cruda

Pohlia longicollis

Pohlia minor

Pohlia elongate

Mnium spinosum

Mnium laevinerve

Mnium marginatum

Plagiomnium acutum

Plagiomnium succulentum

Plagiomnium maximoviczii

Plagiomnium arbusculum

Trachycystis flagellaris

Trachycystis ussuriensis
Rscaled distance cluster combine

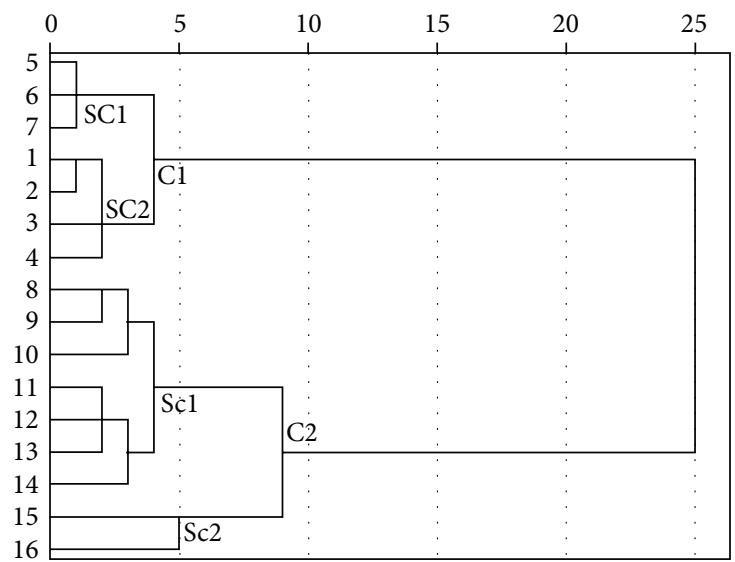

FIgURE 2: Rescaled distance cluster combine. 
TABLE 4: Variance and cumulative variance for the first four PCs from PCA on the 16 moss species data subsets.

\begin{tabular}{lcc}
\hline PC & Variance (\%) & Cumulative variance (\%) \\
\hline PC1 & 83.332 & 83.332 \\
PC2 & 10.784 & 94.116 \\
PC3 & 4.461 & 98.577 \\
PC4 & 0.767 & 99.344 \\
\hline
\end{tabular}

98.58\% of the data variance. Figure 3 shows the 3D scores plot based on the first three PCs. It indicates directly that the species of family Bryaceae, Mielichhoferiaceae (A, Figure 3), and Mniaceae (B, Figure 3) can be grouped in two separate ellipses. The studied species of family Mielichhoferiaceae and Bryaceae form two groups (Figure 3). The Trachycystis species $(15,16)$ exhibit a short-distance relationship with genus Plagionium and Mnium (Figure 3). The molecular evidence indicated that the genus Pohlia was more closely related to family Mniaceae. By contrast, the cluster analysis and PCA data suggest that the species of genus Pohlia (1-4) are more closely related to the species of family Bryaceae (5-7). According to the scatter plots, the species of family Bryaceae is nearer to Mielichhoferiaceae than Mniaceae. Combined with cluster analysis, the PCA results can be used to give rough results of classification among the genera simply.

4.5. FSD Analysis of FTIR Spectral Data. FSD can be used to distinguish the small difference of the functional groups in the fingerprint region [15]. FSD will not change the position and area of the peaks. Besides making the signal peaks narrower, the (1800 to 400$) \mathrm{cm}^{-1}$ range includes the fingerprint region that contains more molecule structure information. Therefore, we use the region $(1800$ to 400$) \mathrm{cm}^{-1}$ for the FSD extraction of spectral features.

Pohlia cruda (1), Bryum argenteum (5), and Mnium spinosum (8) are the type species of genera Pohlia, Bryum and Mnium. In order to further identify them, FSD is used to deal with the FTIR spectra of the three species. The results of FTIR-FSD spectra in the fingerprint region between 1800 and $400 \mathrm{~cm}^{-1}$ are displayed in Figure 4, which shows that the output waveforms of the three species have a marked variation. Certain differences are observed among the three species at the same resolution degree. The $\mathrm{C}=\mathrm{O}$ bend at $1690 \mathrm{~cm}^{-1}$ is found in Bryum argenteum and Mnium spinosum but not in Pohlia cruda. The shape of transmittance bands at $1610 \mathrm{~cm}^{-1}(\mathrm{C}=\mathrm{N})$ and $1312 \mathrm{~cm}^{-1}(\mathrm{~N}=\mathrm{O})$ is different. The shape of transmittance bands and the intensity of transmittance peaks in the fingerprint region are quite different. Thus, FSD can be used to easily classify species in different genera.

4.6. Wavelet Analysis of FTIR Spectral Data. Species that belong to the same genus contain similar chemical components (e.g., protein, carbohydrate, and plant hormones) [40]. FTIR spectra of the same genus exhibit close transmittance values at the same wavenumber. For instance, the FTIR transmittances of the two species in genus Mnium are quite difficult to distinguish. The $1300 \mathrm{~cm}^{-1}$ to $400 \mathrm{~cm}^{-1}$ region

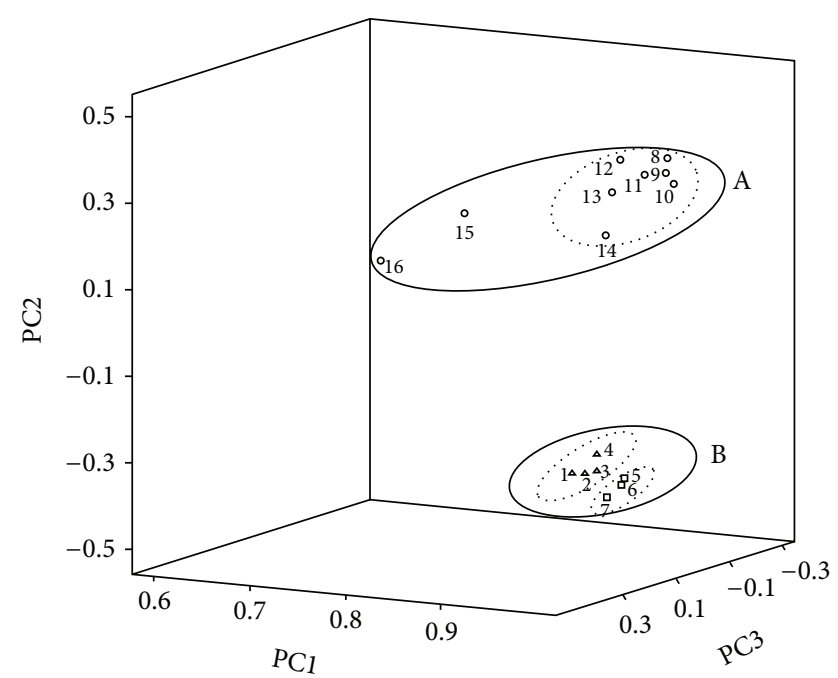

FIGURE 3: 3D plot of FTIR spectra of the 16 moss species based on PCA.

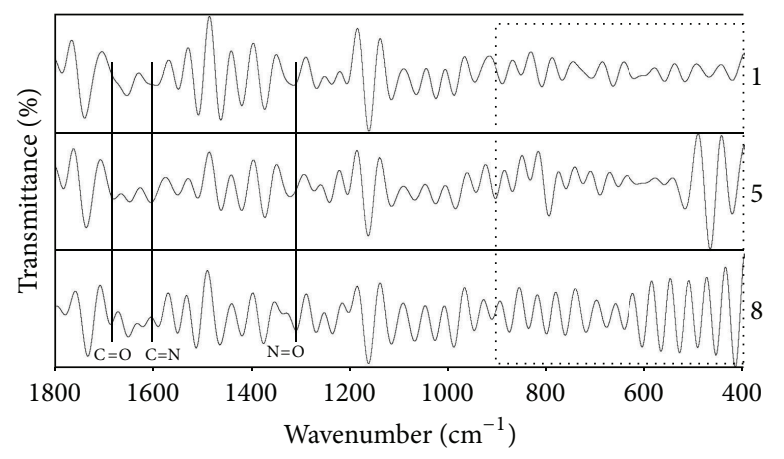

FIGURE 4: FSD-FTIR spectra in the $1800-400 \mathrm{~cm}^{-1}$ region in the whole plants of Pohlia cruda (1), Bryum argenteum (5), and Mnium spinosum (8). Characteristic transmittance bands are indicated at the bottom.

can usually provide higher characteristic information of the spectra [14]. This fingerprint region contains more molecular structural information. Therefore, in our study, DWT was used to extract their features for further classification.

One-dimensional DWT was applied to decompose the FTIR spectral data of Mnium laevinerve (9) and M. marginatum (10) into different frequency bands. The vibration signals were then decomposed up to five levels using Daubechies 4 mother wavelet. The DWT coefficients effectively reflect the features of spectra (Figure 5). Scale 1 contains large noise, which is unsuitable in analyzing the difference of the same genus; determining the differences from Scale 5 is difficult as well. Scales 2-4 show an obvious difference between the two Mnium species. The DWT coefficients of the whole plant of Mnium laevinerve (9) and M. marginatum (10) are different. Therefore, the decomposition levels 2-4 in the DWT domain are chosen as a variable characteristic extraction region. In Scales 2-4, different species in the same genus can be simply and effectively identified. The results prove that DWT can be used to extract the features of the FTIR transmittances 

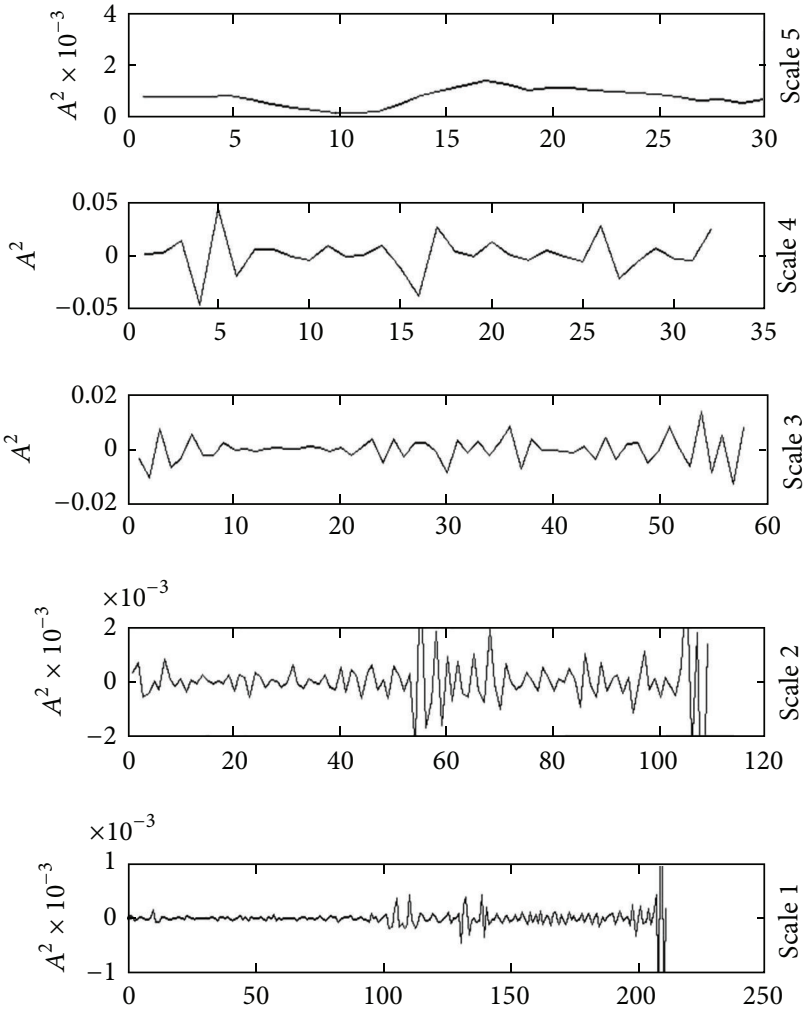

(a)
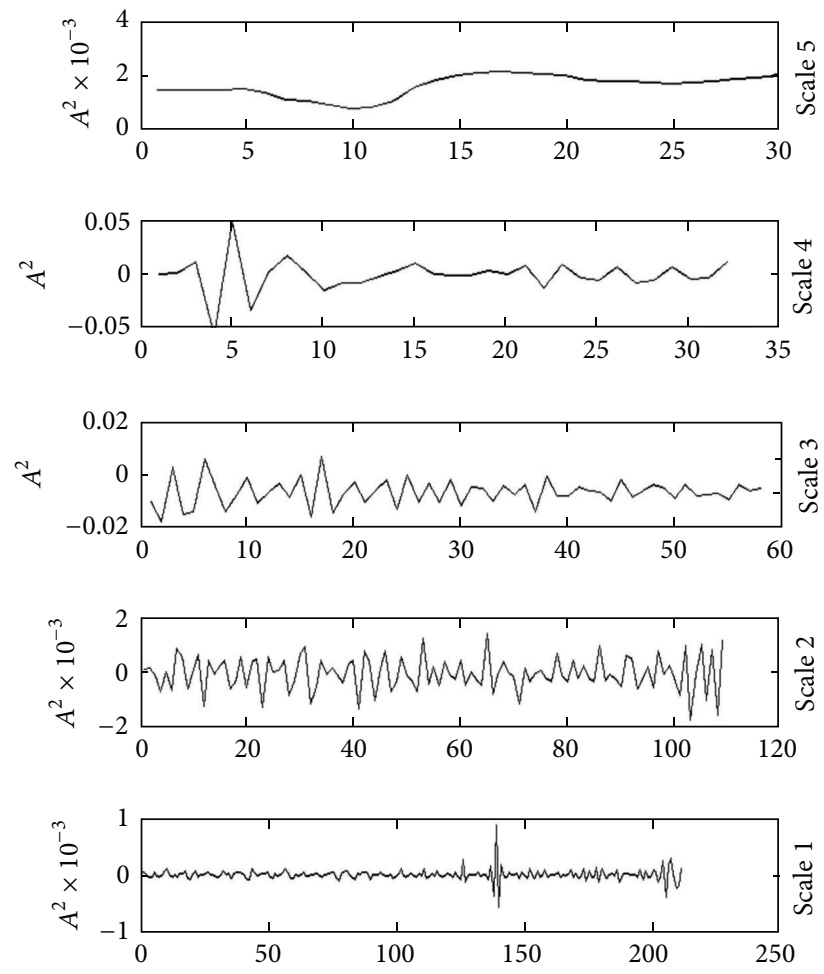

(b)

Figure 5: Results of the multiresolution decomposition for the two Mnium species. FTIR spectra with DWT. (a) Mnium laevinerve (9) and (b) M. marginatum (10).

of the plants in the same genus. Thus, DWT can be used to subdivide bryophytes species.

\section{Conclusion}

In recent years, the phylogenetic relationships of family Mielichhoferiaceae, Bryaceae, and Mniaceae are still unclear. The traditional circumscriptions are based mainly on peristome characters, making the classification of the three taxa difficult. Results of the present analysis show that FTIR spectroscopy in combination with PCA and cluster analyses can be used to discriminate the genera in Mielichhoferiaceae, Bryaceae, and Mniaceae. Recent studies based on molecular data indicated that genus Pohlia belongs to the family Mniaceae [41]. In our study, we find that genus Pohlia is more related to Bryaceae with a good support using chemical methods on the basis of their different chemical composition. The PCA results show that the Pohlia species are not closely related to the species of Mniaceae, and the three families can be basically separated from each other. FSD and DWT are used to extract the features and enhance the differences between the species in the fingerprint region. The two Mnium species are successfully identified by FTIR spectroscopy method combined with DWT. Results of the FTIR spectroscopy combined with cluster analyses and PCA can also be used to identify different genera and families of mosses; FTIR spectroscopy method combined with DWT is suitable for discriminating different species of the same genus. The results show the possibility of the use of optical methods, such as FTIR method, in differentiating the genera and species of mosses. FTIR combined with chemometric methods for identification of mosses is rapid and efficient, and this could enable routine laboratories to facilitate identification procedures on mosses with the same technology.

\section{Disclosure}

Zhen Cao and Yongying Liu are co-first authors.

\section{Conflict of Interests}

The authors declare that there is no conflict of interests regarding the publication of this paper.

\section{Acknowledgments}

This research was supported by the Natural Science Foundation of China (31370237, 31070184) and the Natural Science Foundation of Hebei Province (C2012205026). 


\section{References}

[1] L. Foan, S. Leblond, C. Thöni et al., "Spatial distribution of PAH concentrations and stable isotope signatures $\left(\delta^{13} \mathrm{C}, \delta^{15} \mathrm{~N}\right)$ in mosses from three European areas-characterization by multivariate analysis," Environmental Pollution, vol. 184, pp. 113122, 2014.

[2] M. R. Crosby, R. E. Magill, B. Allen et al., In a Checklist of the Mosses, Missouri Botanical Garden, St. Louis, Miss, USA, 1999.

[3] B. J. Crandall-Stotler and S. E. Bartholomew-Began, "Morphology of mosses (Phylum Bryophyta)," in Flora of North America North of Mexico, vol. 27, pp. 3-13, Flora of North America Editorial Committee, New York, NY, USA, 2007.

[4] J. Guerra, J. F. Jiménez-Martínez, M. J. Cano, and J. A. Jiménez-Fernández, "A contribution to the phylogenetic study of Mielichhoferiaceae-Mniaceae (Bryophyta) based on molecular sequence data," Nova Hedwigia, vol. 93, no. 1-2, pp. 47-56, 2011.

[5] C. J. Cox and T. A. J. Hedderson, "Phylogenetic relationships among the ciliate arthrodontous mosses: evidence from chloroplast and nuclear DNA sequences," Plant Systematics and Evolution, vol. 215, no. 1-4, pp. 119-139, 1999.

[6] C. J. Cox and T. A. J. Hedderson, "Phylogenetic relationships within the moss family Bryaceae based on chloroplast DNA evidence," Journal of Bryology, vol. 25, no. 1, pp. 31-40, 2003.

[7] C. J. Cox, B. Goffinet, A. Jonathan Shaw, and S. B. Boles, "Phylogenetic relationships among the mosses based on heterogeneous Bayesian analysis of multiple genes from multiple genomic compartments," Systematic Botany, vol. 29, no. 2, pp. 234-250, 2004.

[8] C. Y. Wang and J. C. Zhao, "Phylogeny of Ptychostomum (Bryaceae, Musci) inferred from sequences of nuclear ribosomal DNA internal transcribed spacer (ITS) and chloroplast rps4," Journal of Systematics and Evolution, vol. 47, no. 4, pp. 311-320, 2009.

[9] V. F. Brotherus, "Musci," in Engler a, Prantl K, eds. Die Natürlichen Pflanzenfamilien, vol. 10-11, Wilhelm Engelmann, Leipzig, Germany, 2nd edition, 1924-1925.

[10] C. Y. Wang, D. L. Li, and J. C. Zhao, "Phylogeny position of the genus Pohlia Hedw: evidence form the nuclear ribosomal DNA ITS region," Bulletin of Botanical Research, vol. 30, pp. 517-526, 2010.

[11] C. G. Cheng, J. Liu, H. Wang, and W. Xiong, "Infrared spectroscopic studies of Chinese medicines," Applied Spectroscopy Reviews, vol. 45, no. 3, pp. 165-178, 2010.

[12] L. Mariey, J. P. Signolle, C. Amiel, and J. Travert, "Classification and identification of bacteria by Fourier transform infrared spectroscopy," Vibrational Spectroscopy, vol. 26, pp. 151-159, 2001.

[13] A. Naumann, "Discrimination, classification, identification of microorganisms using FTIR spectroscopy and chemometrics," Analyst, vol. 134, pp. 1215-1223, 2009.

[14] C. G. Cheng, J. Liu, W. Q. Cao, R. W. Zheng, H. Wang, and C. J. Zhang, "Classification of two species of Bidens based on discrete stationary wavelet transform extraction of FTIR spectra combined with probability neural network," Vibrational Spectroscopy, vol. 54, no. 1, pp. 50-55, 2010.

[15] T. Hu, W. Jin, and C. Cheng, "Classification of five kinds of moss plants with the use of Fourier transform infrared spectroscopy and chemometrics," Spectroscopy, vol. 25, no. 6, pp. 271-285, 2011.
[16] K. L. A. Chan and S. G. Kazarian, "Attenuated total reflectionfourier transform infrared imaging of large areas using inverted prism crystals and combining imaging and mapping," Applied Spectroscopy, vol. 62, no. 10, pp. 1095-1101, 2008.

[17] Z. Movasaghi, S. Rehman, and I. U. Rehman, "Fourier transform infrared (FTIR) spectroscopy of biological tissues," Applied Spectroscopy Reviews, vol. 43, no. 2, pp. 134-179, 2008.

[18] M. de Luca, W. Terouzi, G. Ioele et al., "Derivative FTIR spectroscopy for cluster analysis and classification of morocco olive oils," Food Chemistry, vol. 124, no. 3, pp. 1113-1118, 2011.

[19] R. Rana, G. Müller, A. Naumann, and A. Polle, "FTIR spectroscopy in combination with principal component analysis or cluster analysis as a tool to distinguish beech (Fagus sylvatica L.) trees grown at different sites," Holzforschung, vol. 62, no. 5, pp. 530-538, 2008.

[20] C. G. Cheng, Y. M. Tian, and C. J. Zhang, "Research of recognition method between Semen cuscutae and its sibling plant Japanese dodder seed based on FTIR-CWT and ANN classification method," Acta Chimica Sinica, vol. 66, no. 7, pp. 793-798, 2008.

[21] C.-J. Zhang and C.-G. Cheng, "Identification between Stephania tetrandra S. Moore and Stephania cepharantha Hayata by CWTFTIR-RBFNN," Spectroscopy, vol. 22, no. 5, pp. 371-386, 2008.

[22] I. Daubechies, "The wavelet transform, time-frequency localization and signal analysis," IEEE Transactions on Information Theory, vol. 36, no. 5, pp. 961-1005, 1990.

[23] H. Lü, C. Cheng, X. Tang, and Z. Hu, "FTIR spectrum of Hypericum and Triadenum with reference to their identification," Acta Botanica Sinica, vol. 46, no. 4, pp. 401-406, 2004.

[24] M. Jackson, H. H. Mantsch, and R. A. Meyers, "Infrared spectroscopy ex vivo tissue analysis," in Encyclopedia of Analytical Chemistry, pp. 131-156, Wiley, Chichester, UK, 2000.

[25] M. Forina, P. Oliveri, S. Lanteri, and M. Casale, "Class-modeling techniques, classic and new, for old and new problems," Chemometrics and Intelligent Laboratory Systems, vol. 93, no. 2, pp. 132148, 2008.

[26] K. I. Poulli, G. A. Mousdis, and C. A. Georgiou, "Classification of edible and lampante virgin olive oil based on synchronous fluorescence and total luminescence spectroscopy," Analytica Chimica Acta, vol. 542, no. 2, pp. 151-156, 2005.

[27] B. P. Marchant, "Time-frequency analysis for biosystems engineering," Biosystems Engineering, vol. 85, no. 3, pp. 261-281, 2003.

[28] A. Subasi, "Medical decision support system for diagnosis of neuromuscular disorders using DWT and fuzzy support vector machines," Computers in Biology and Medicine, vol. 42, no. 8, pp. 806-815, 2012.

[29] D. Sripathi, Efficient Implementations of Discrete Wavelet Transforms Using FPGAs [M.S. thesis], Florida State University, 2003.

[30] S. T. Gorgulu, M. Dogan, and F. Severcan, "The characterization and differentiation of higher plants by Fourier transform infrared spectroscopy," Applied Spectroscopy, vol. 61, no. 3, pp. 300-308, 2007.

[31] R. Salzer, G. Steiner, H. H. Mantsch, J. Mansfield, and E. N. Lewis, "Infrared and Raman imaging of biological and biomimetic samples," Fresenius' Journal of Analytical Chemistry, vol. 366, no. 6-7, pp. 712-726, 2000.

[32] D. Helm, H. Labischinski, G. Schallehn, and D. Naumann, "Classification and identification of bacteria by Fouriertransform infrared spectroscopy," Journal of General Microbiology, vol. 137, no. 1, pp. 69-79, 1991. 
[33] D. Helm, H. Labischinski, and D. Naumann, "Elaboration of a procedure for identification of bacteria using Fourier-Transform IR spectral libraries: a stepwise correlation approach," Journal of Microbiological Methods, vol. 14, no. 2, pp. 127-142, 1991.

[34] P. Q. Yu, "Applications of hierarchical cluster analysis (CLA) and principal component analysis (PCA) in feed structure and feed molecular chemistry research, using synchrotron-based fourier transform infrared (FTIR) microspectroscopy," Journal of Agricultural and Food Chemistry, vol. 53, no. 18, pp. 7115-7127, 2005.

[35] E. K. Kemsley, P. S. Belton, M. C. Cann, S. Ttofis, R. H. Wilson, and I. Delgadillo, "A rapid method for the authentication of vegetable matter using Fourier transform infrared spectroscopy," Food Control, vol. 5, pp. 241-243, 1994.

[36] Y. W. Lai, E. Katherine Kemsley, and R. H. Wilson, "Potential of fourier transform infrared spectroscopy for the authentication of vegetable oils," Journal of Agricultural and Food Chemistry, vol. 42, no. 5, pp. 1154-1159, 1994.

[37] M. Defernez, E. K. Kemsley, and R. H. Wilson, "Use of infrared spectroscopy and chemometrics for the authentication of fruit purees," Journal of Agricultural and Food Chemistry, vol. 43, no. 1, pp. 109-113, 1995.

[38] G. D. Sockalingum, W. Bouhedja, P. Pina, P. Allouch, C. Bloy, and M. Manfait, "FT-IR spectroscopy as an emerging method for rapid characterization of microorganisms," Cellular and Molecular Biology, vol. 44, no. 1, pp. 261-269, 1998.

[39] J. Yang, X. You, Y. Y. Tang, and B. Fang, "A watermarking scheme based on discrete non-separable wavelet transform," in Proceedings of the 2nd Iberian Conference on Pattern Recognition and Image Analysis (IbPRIA '05), pp. 427-434, Estoril, Portugal, June 2005.

[40] Y. Asakawa, A. Ludwiczuk, and F. Nagashima, "Phytochemical and biological studies of bryophytes," Phytochemistry, vol. 91, pp. 52-80, 2013.

[41] W. Frey, M. Stech, and E. Fischer, "Bryophytes and seedless vascular plants," in Syllabus of Plant Families, pp. 193-198, Gebr. Borntraeger Verlagsbuchhandlung, Berlin, Germany, 2009. 

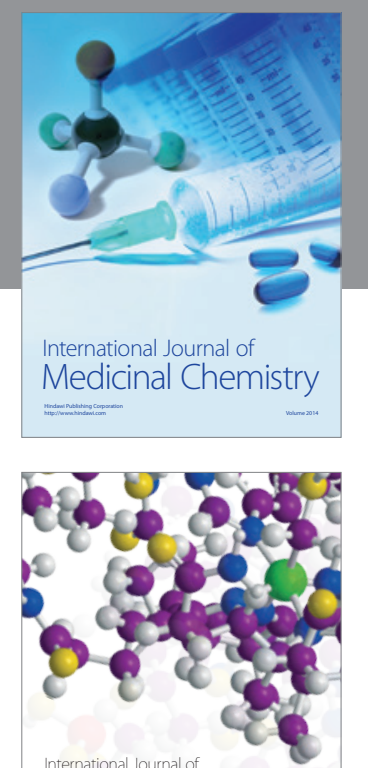

\section{Carbohydrate} Chemistry

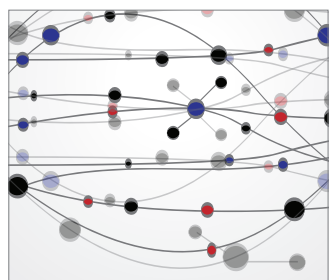

The Scientific World Journal
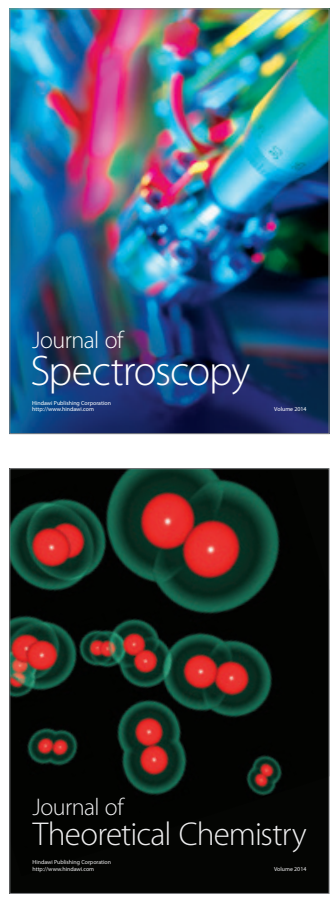
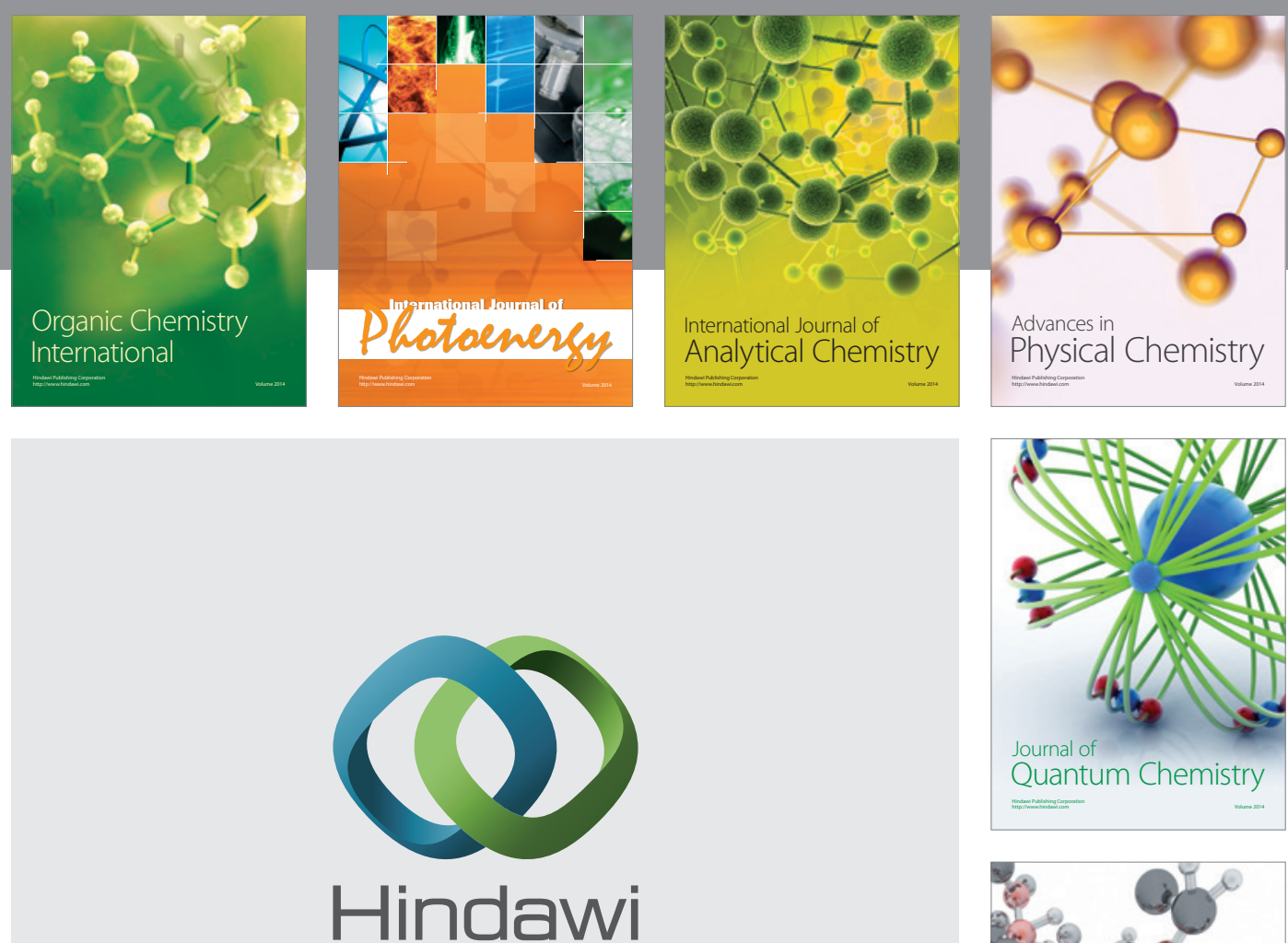

Submit your manuscripts at

http://www.hindawi.com

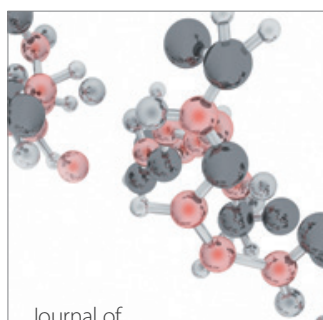

Analytical Methods

in Chemistry

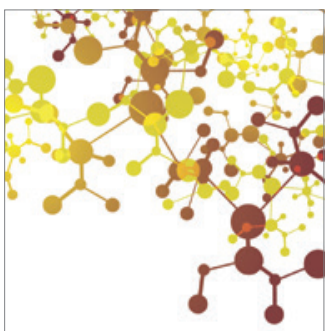

Journal of

Applied Chemistry

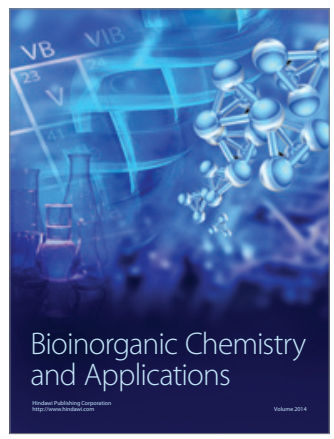

Inorganic Chemistry
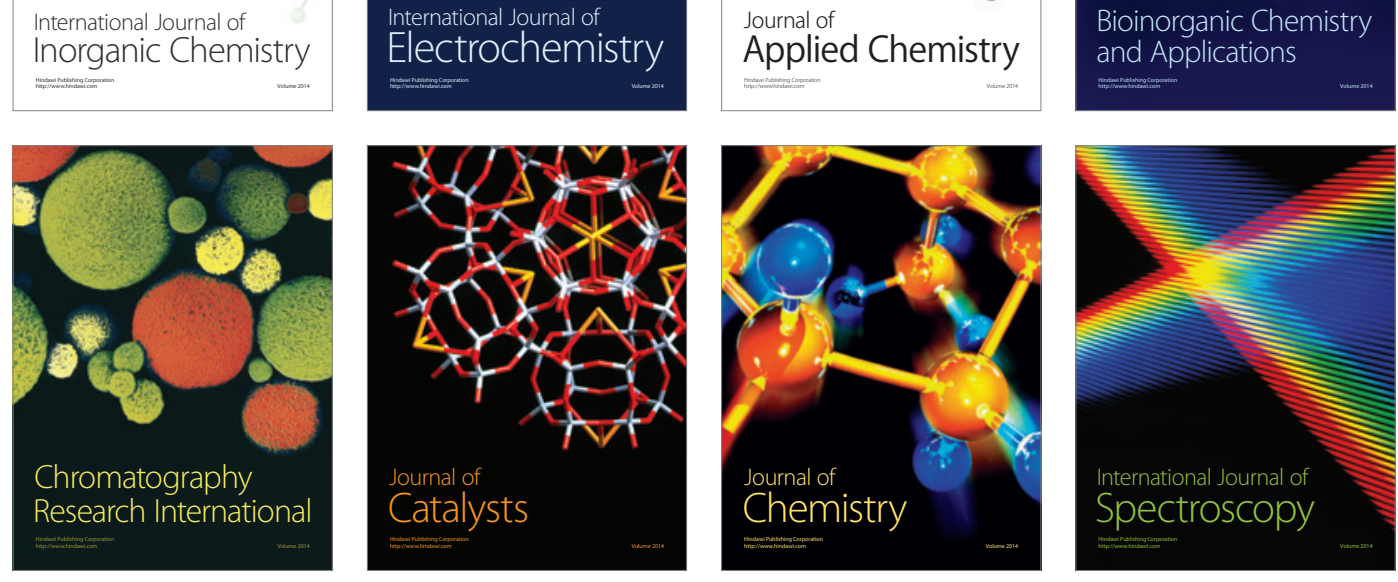